\title{
TEST BENCH DESIGN FOR WIRELESS ENERGY TRANSFER USING THE RESONANT INDUCTIVE COUPLING METHOD
}

\author{
Ítala Liz da Conceição Santana Silva ${ }^{a}$, Jorge Palma Conceiçãoa,b \\ a Senai Cimatec, Brasil, \\ ${ }^{b}$ Centro de Competência em Sistemas Elétricos.
}

\begin{abstract}
The resonant inductive coupling is a form of wire energy transfer based on the principle of electromagnetic induction. This technique provides more mobility to electronic devices. Also, as it does not need a physical connection to recharge batteries, it does not cause discomfort to users. However, it presents limitations such as reduced mobility, flexibility, and autonomy; therefore, studies of techniques related to wireless energy transfer have intensified in recent years. However, this technology is still considered inefficient for loading equipment due to its range and low delivery power, as well as the absence of control techniques. Based on the results of studies, the use of the resonant inductive coupling method to transfer energy to low-power loads in different areas has been intensified.
\end{abstract}

Keywords: Resonant inductive coupling, low power loads, efficiency, wireless energy transfer.

\section{PROJETO DE BANCADA DE TESTE PARA TRANSFERÊNCIA DE ENERGIA SEM FIO UTILIZANDO O MÉTODO DO ACOPLAMENTO INDUTIVO RESSONANTE}

Resumo: O acoplamento indutivo ressonante é uma forma de transferência de energia em fio baseada no princípio da indução eletromagnética. Essa técnica proporciona mais mobilidade aos dispositivos eletrônicos. Também, por não necessitar de conexão física para recarga de baterias, não causa incômodo aos usuários. Entretanto, apresenta limitações como mobilidade reduzida, flexibilidade e autonomia, por isso, estudos de técnicas relacionados a transferência de energia sem fio se intensificaram nos últimos anos. Entretanto, essa tecnologia ainda é considerada pouco eficiente para carregamento de equipamentos devido a seu alcance e baixa potência de entrega, bem como ausência de técnicas de controle. Baseado em resultados de estudos, intensificou-se o uso do método de acoplamento indutivo ressonante para transferência de energia para cargas de baixa potência voltados a diversas áreas.

Palavras-chave: Acoplamento indutivo ressonante; cargas de baixa potência; eficiência; transferência de energia sem fio. 


\section{INTRODUCTION}

The first studies related to wireless power transfer (WPT) were developed by Nikola Tesla in the late 19th century. In these studies, he was able to feed vacuum tubes in a closed environment [1]. The use of magnetic fields is the basis for the main methods of wireless energy transfer, which can be classified as a near field or far-field. They differ from each other by the transmission range and the propagation of the signal.

The near field transfer method uses the induction of time-varying fields to transport energy, which can be done through capacitive or inductive coupling. At the same time, transmission via far-field is done by irradiation of electromagnetic waves. The most common forms are microwave, optics, and laser [2]. Farfield transfers require the absence of obstacles along the way and have high electromagnetic radiation, which is seldom used. The transmission method most used today is the resonant inductive coupling, the main object of study of this project.

This project seeks to study and improve techniques related to wireless energy transfer applied to electric mobility and also train people to meet future market demands. As a result, it is planned to build a small test bench for wireless energy transfer using the short-distance and resonant inductive coupling method for low power loads.

\subsection{Theoretical Foundation}

WPT can be applied in several areas. In industry, it can be used to power sensors and actuators. In the distribution of energy, it is expected to be used by feeding remote and rugged access areas as well as in mining. It can also carry military electronic systems that need to withstand sudden variations in the environment. In the medical field, it can act in the feeding of implants and biomedical sensors. In the auto industry, the increase in greenhouse gases and ecological issues motivate the development of hybrid and electric cars that use batteries. Although promising, the need for batteries is a negative point, resulting in studies of charging techniques to increase their autonomy [2].

The use of wireless power transfer technology has several advantages, such as transmission in environments that are unable to use cables, no supply interruptions due to network failures, elimination of risks by electric shocks, and the possibility of connecting several receivers to a single transmitter. However, it has some disadvantages, such as the necessity of adapting existing equipment that doesn't have this technology, possible consequences of the effect of electromagnetic radiation in the long term, low efficiency when compared to other models of energy transmission, and high cost of implantation. In the WPT system design, several factors must be analyzed. Some of them are power and load current, response time, stability, and influence of harmonics. As a result, the use of WPT on a large scale has innumerable challenges, for example, improving efficiency, decreasing costs, and, consequently, establish a standard of their use [3].

As mentioned, the resonant inductive coupling is the most used method for WPT. It operates with frequencies up to dozens of $\mathrm{MHz}$. In inductive coupling, the transmitter and receiver are in an environment of low magnetic permeability, making the coupling weak and the transfer of energy unviable to traditional frequencies. Also, the magnetic field disperses quickly in all directions in the middle, being a waste to transfer energy in this way. When using a resonant 
coupling, the transmitter and receiver operate at the resonant frequency, reducing losses expressively. Due to this frequency, the source used in the circuit must be AC (to generate a variable magnetic field and adjustable frequency), and it must also have an amplification circuit. For the transmission, there will be a compensation circuit and, finally, a rectifier circuit that will supply the load. Figure 1 shows the diagram of the system to be developed in the project:

Figure 1: Schematic of the WPT System [6]

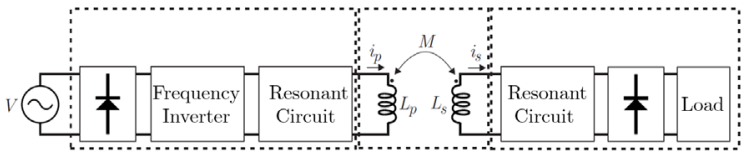

The compensation diagram uses LC circuits to increase efficiency, reducing losses due to harmonics and electromagnetic interference. Their circuits vary according to the operating condition. At high frequencies, the current suffers losses due to the Skin effect. Thus, to reduce these losses, it is recommended to use wires Litz, hollow, or with a more extensive crosssection. As the magnetic field is not directional, it is unnecessary to use any device to guide it. However, even if low, there will always be losses due to dispersion.

Other important factors must be considered, such as the quality factor $(\mathrm{Q})$ and the coupling factor ( $\mathrm{k}$ ). The quality factor guarantees an "optimal" resonance for high frequencies, and the value of " $k$ " is directly linked to the distance and position of the coils. The higher the number of magnetic field lines, the greater the coupling coefficient between them. However, as the coupling is not perfect, it is necessary to use capacitors to compensate for inductive losses. The type of connection of the capacitors (series or parallel) will depend on the source and the characteristics of the load [4].

To maximize power transfer, an impedance match must be made. Therefore, the highest transfer values occur at the resonance frequency. In the design of an experimental system, the impedance matching is a significant factor to guarantee adequate overall efficiency for the course. According to the research developed for this work, the antenna most used in models of wireless energy transfer by resonant modes is the square or spiral antenna, as it has a low radiation resistance.

\section{METHODOLOGY}

Based on the bibliography found in previous studies about WPT, the most appropriate parameters for the project could be established. After that, the coil geometry and the following parameters were defined: coil length and diameter, ohmic losses, self-inductance, mutual Inductance, coupling factor, quality factor, power supplied to the load, and system efficiency, etc.

The coupling factor $(k)$ is given by the relative position between the emitter and the receiver. It's also influenced by the winding geometries of both, which result in their own inductances, the materials that make up the inductors, and the interactions with nearby bodies. Its value decreases with the distance and alignment of the coils, making the use of the resonant inductive coupling restricted to shortdistance applications. For this coupling to be maximum, the coils must be very close and completely aligned. In practice, there are many techniques to improve the magnetic coupling, one of which is to increase the width of the coils. However, depending on the application, this technique becomes a little feasible. Therefore, this parameter 
needs to be known so that the transfer can be characterized in a converter [7]. The greater the number of magnetic field lines received by the receiver, the greater the coefficient of coupling between them. However, as the coupling is not perfect, it is necessary to use capacitors to create a compensation circuit for inductive losses. The coupling factor value varies between 0 and 1 and can be obtained through the equation below:

$$
k=\frac{1}{\left[1+2^{\frac{2}{3}}\left(\frac{d}{\sqrt{a \cdot b}}\right)^{2}\right]^{\frac{3}{2}}}
$$

$\mathrm{d}$ is the distance between the coils, $a$ and $b$ are the radio of the transmitting and receiving coils, respectively.

The quality factor $(Q)$ usually has a high value for the working frequency. This parameter counterbalances the drop in the coupling factor with the variation in the distance so that efficiency can be maintained.

The increase in the value of $Q$ reduces the parasitic resistances and, consequently, the losses in the system. It can be optimized by reducing the losses due to the high frequency. $Q$ represents a relationship between the energy that the system stores and the energy that it dissipates. It is a parameter for coils and compensation circuits and can be mathematically described as:

$$
Q=\omega \frac{L}{R}=\frac{1}{\omega R C}
$$

The length of the conductor $(l)$ used is a significant constructive parameter in the calculation of auto inductance. It is calculated using an integral that has no analytical solution, requiring great computational effort to be solved. For the planar spiral coil, the length of the conductor can be obtained through the Archimedes spiral equation that can be approximated by:

$$
l=\pi \cdot x \cdot y^{2}+\pi y\left(2 \frac{d_{i n t}}{2}+x\right)
$$

Where $x$ is the diameter of the conductor and $y=\frac{\left(\frac{d_{\text {ext }}}{2}-\frac{d_{\text {int }}}{2}\right)}{x}, d_{\text {ext }}$ and $d_{\text {int }}$ are the inner and outer diameters of the coil, respectively.

Another important parameter in the design of the resonant system is self-inductance. In the literature, there are several approaches regarding coil models and geometries, as well as their advantages and disadvantages. In addition, there are several ways to calculate coil auto-inductance.

The self-inductance $(L)$ of the planar circular coil is calculated using the following equation:

$$
L=\frac{\mu . N^{2}\left(d_{\text {int }}+d_{\text {ext }}\right)}{4}\left[\ln \left(\frac{2.46}{\phi}+0.20 \phi^{2}\right)\right]
$$

Where $\phi=\left(d_{\text {ext }}-d_{\text {int }}\right) /\left(d_{\text {ext }}+d_{\text {int }}\right)$.

Mutual Inductance $(M)$ measures the interaction between the primary and the secondary. Faraday's Law and Lenz explain the theory that governs Mutual Inductance. The higher the mutual Inductance, the greater the number of lines of the magnetic field delivered to the receiver. The value of $M$ is given by:

$$
M=\frac{\mu \cdot N_{1} \cdot N_{2} \cdot r_{t x}^{2} \cdot r_{r x}^{2}}{\sqrt{\left(r_{t x}+r_{r x}\right)^{2}+d^{2}}\left[\left(r_{t x}-r_{r x}\right)+d^{2}\right]}
$$

Where $r$ is the radius of the transmitting and receiving coils, this value of $M$ is obtained for two spiral curls. Another way to get the benefit of $M$ is by using the approximate equation of $\mathrm{k}$, making $M=k \sqrt{L_{p} \cdot L_{s}}$, Lp and Ls being the primary and secondary inductances of the system, respectively. 
Several ohmic losses can be calculated in a WPT system, and their values are directly related to the frequency of work. For frequencies below $2 \mathrm{GHz}$, DC resistance and capacitor resistance must be considered. These values can be calculated by:

$$
\begin{gathered}
R_{d c}=\rho \frac{l}{A}, R_{S}=R_{d c} \frac{x}{\delta\left(1-e^{\left.\frac{-x}{\delta}\right)}\right.}, \delta= \\
\sqrt{\frac{\rho}{\pi \cdot \mu . f}}, \mu=\mu_{r} \cdot \mu_{0}, R_{a c}=\frac{l . \rho}{(\delta \pi(x-\delta))} \\
\text { e } R_{c a p}=\frac{E S R}{\omega C .100}
\end{gathered}
$$

Where $\delta$ is the depth of penetration, this resistance comes from skin effect.

Thus, it's possible to conclude that resistors, inductors, and mutual Inductance are constructive parameters of the coil and depend only on the physical dimensions such as geometry, number of turns, material, alignment, and distance.

After this methodologic study, the adopted values were submitted to tests. The results of the simulations are presented in "Results and Discussion."

\section{RESULTS AND DISCUSSION}

Several tests of parameters were carried out, such as variation in the distance between the coils, conductor diameter, coil diameter, spacing between turns, and a number of windings. After these tests, it was concluded that the best efficiency results are for coils whose transmitter (N1) is slightly larger than the receiver (N2), as shown in Figure 2. Also, it must be used the smallest spacing between the coils and the conductor diameter must be defined by the current capacity that must be delivered to the load.
Figure 2: Efficiency results based on the number of the coil - Prepared by the author

(a) Different values for N1 and N2

(b) N1 and N2 equals
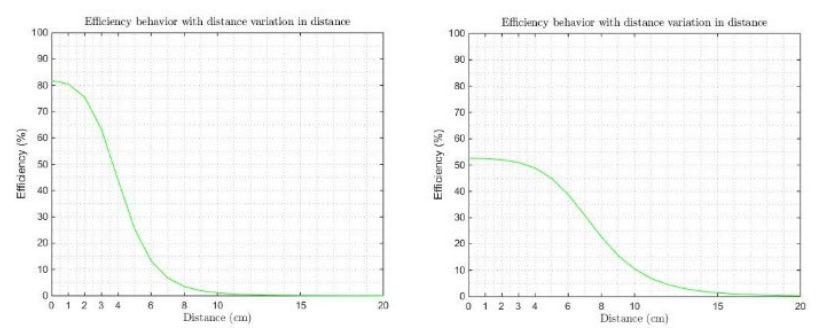

The resonance frequency of the systems studied varies between $85 \mathrm{kHz}$ and $13.56 \mathrm{MHz}$. The use of the frequency of $13.56 \mathrm{MHz}$ showed a little efficiency. For the proposed coils, tests were performed using two working frequencies of $85 \mathrm{kHz}$ and $500 \mathrm{kHz}$, respectively, where the results shown in Figure 3 were obtained.

Figure 3. Frequency behavior with distance variation for $85 \mathrm{kHz}$ and $500 \mathrm{kHz}$, respectively. - Prepared by the author
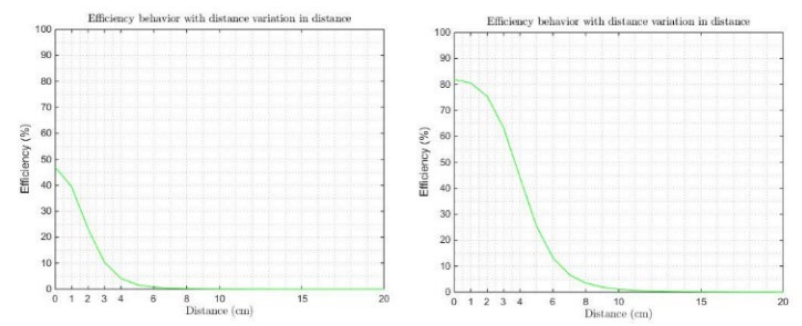

Based on Figures 2 and 3, it can be concluded that the best efficiency results are for an intermediate frequency value, where the number of turns of the primary must be slightly higher than the number of turns of the secondary, and both have few turns.

According to the test results, the parameters of the coil were defined, and the necessary variables were calculated to obtain the efficiency of the system. The results obtained are shown in Table 1: 
Table 1. System Parameters Prepared by the author

\begin{tabular}{|l|l|}
\multicolumn{1}{|c|}{\begin{tabular}{c}
\multicolumn{1}{c|}{ Constructive } \\
Parameter
\end{tabular}} & \multicolumn{1}{c|}{ Value } \\
\hline $\begin{array}{l}\text { Working frequency } \\
\text { Number of turns Tx } \\
\left(\boldsymbol{N}_{\mathbf{1}}\right)\end{array}$ & $500 \mathrm{kHz}$ \\
\hline $\begin{array}{l}\text { Number of turns Rx } \\
\left(\boldsymbol{N}_{\mathbf{2}}\right)\end{array}$ & 10 \\
\hline $\begin{array}{l}\text { Coil inner diameter } \\
\left(\boldsymbol{d}_{\boldsymbol{i n}}\right)\end{array}$ & $1 \mathrm{~cm}$ \\
\hline $\begin{array}{l}\text { Conductor diameter } \\
(\boldsymbol{w})\end{array}$ & $2,052 \mathrm{~mm}$ \\
\hline $\begin{array}{l}\text { Spacing between } \\
\text { turns }(\boldsymbol{s})\end{array}$ & $0,25 \mathrm{~mm}$ \\
\hline $\begin{array}{l}\text { Coil outside diameter } \\
\text { Tx }\left(\boldsymbol{d}_{\text {ext }}\right)\end{array}$ & $10,21 \mathrm{~cm}$ \\
\hline $\begin{array}{l}\text { Coil outside diameter } \\
\text { Rx }\left(\boldsymbol{d}_{\text {ext }}\right)\end{array}$ & $5,6 \mathrm{~cm}$ \\
\hline Coil length Tx $\left(\boldsymbol{l}_{\boldsymbol{T} x}\right)$ & $3,81 \mathrm{~m}$ \\
\hline Coil length Rx $\left(\boldsymbol{l}_{\boldsymbol{R} x}\right)$ & $1,10 \mathrm{~m}$ \\
\hline
\end{tabular}

After defining the parameters above, the compensation circuit was dimensioned. There are several compensation topologies for WPT systems. Due to simplicity and efficiency, the topology adopted was series-series. In this topology, a capacitor is used in series with each coil to eliminate the system's reactance. Figure 4 shows the inductive link circuit with series-series compensation:

Figure 4. Series-series compensation circuit [6]

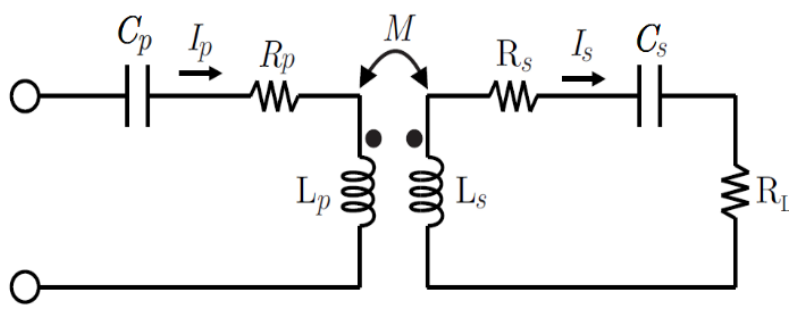

The calculated parameters are shown in Table 2:
Table 2. Settings of the inductive link with series-series compensation

\begin{tabular}{|c|c|}
\hline Parameter & $\begin{array}{l}\text { Value } \\
\text { obtained }\end{array}$ \\
\hline $\begin{array}{l}\text { Primary self-inductance } \\
\left(L_{p}\right)\end{array}$ & $17,35 \mu H$ \\
\hline $\begin{array}{l}\text { Secondary self- } \\
\text { inductance }\left(L_{s}\right)\end{array}$ & $2,82 \mu H$ \\
\hline Primary capacitance $\left(C_{p}\right)$ & $5,84 n F$ \\
\hline $\begin{array}{l}\text { Secondary capacitance } \\
\left(C_{s}\right)\end{array}$ & $35,96 n F$ \\
\hline Mutual Inductance $(M)$ & $\begin{array}{c}7 \mu H \\
-0,0229 \mu H\end{array}$ \\
\hline Primary resistance $\left(R_{p}\right)$ & $7,2 \Omega$ \\
\hline $\begin{array}{l}\text { Secondary resistance } \\
\left(R_{s}\right)\end{array}$ & $5,0 \Omega$ \\
\hline Load resistance $\left(R_{L}\right)$ & $2,5 \Omega$ \\
\hline
\end{tabular}

The encapsulation of the coil must shield it from external influences to reduce losses due to dispersion. The materials most used in this process are insulators in general, such as glass and wood. The work of [1] was used as a reference to encapsulate the coils of the current system, presented in Figure 5 and Figure 6, respectively.

Figure 5. Coil encapsulation proposed by [1]

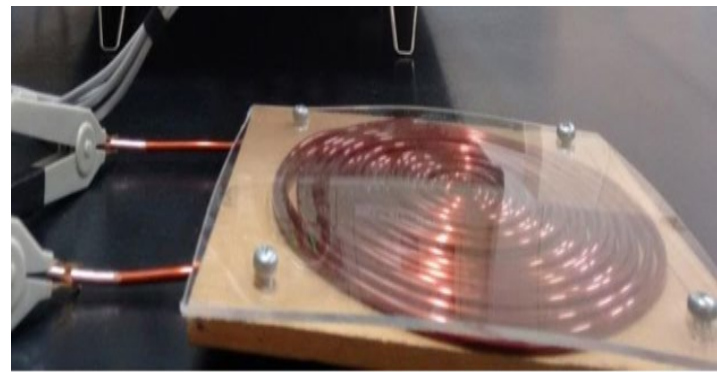

Figure 6: Test coils design for the work - Prepared by the author 

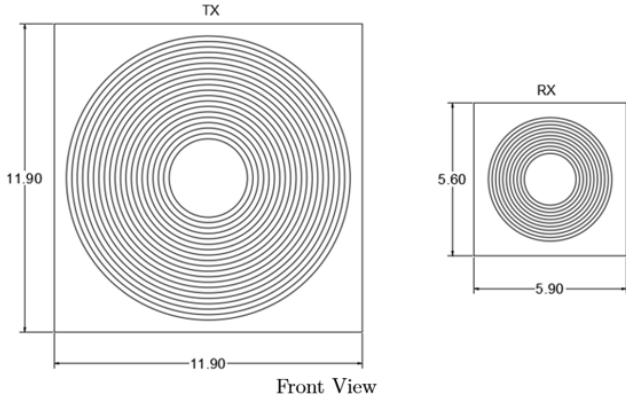

In the proposed system by the

Figure 6, the encapsulation, was defined using acrylic with fixation through non-metallic material, so it doesn't influence the magnetic field lines.

The coil for this project will be constructed using enameled copper wire. With the dimensions of the coil, the sizes of the encapsulation of the transmitter and receiver of the proposed system were defined, as shown in Figure 7.

Figure 7. Bench proposed by [5]

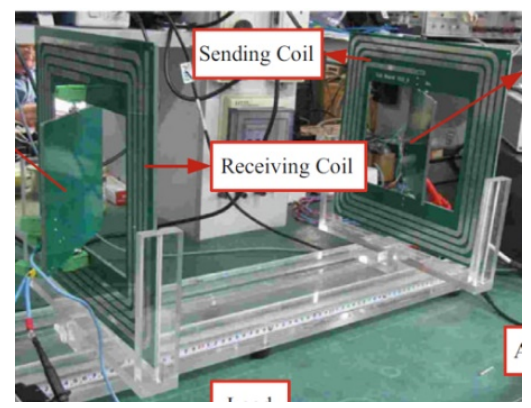

Based on the figures above, a model of suitable dimensions was created for this work. An outline is shown in Figure 8.

Figure 8. 3D view for the system bench proposal - Prepared by the author

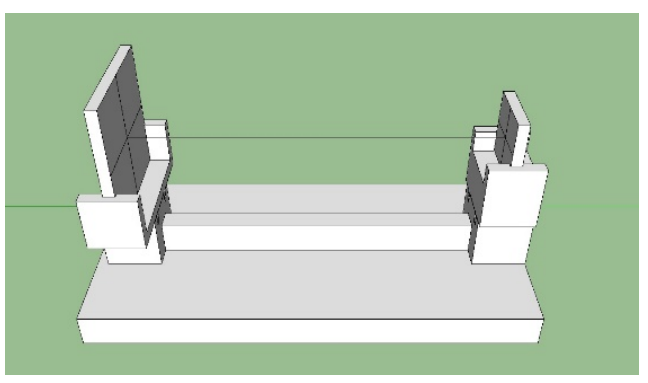

With the bench details defined, the next stage of the project consists of acquiring the materials and assembling the apparatus. Table 3 shows the expected results.

Table 3.Expected Results - Prepared by the author

\begin{tabular}{|l|c|c|c|}
$\begin{array}{c}d \\
(\mathrm{~cm})\end{array}$ & $\mathrm{k}$ & $\begin{array}{c}M \\
(\mu H)\end{array}$ & $\begin{array}{c}\eta \\
(\%)\end{array}$ \\
\hline $\mathbf{0}$ & 1,00 & 6,9915 & 81,79 \\
\hline $\mathbf{1}$ & 0,85 & 5,9704 & 80,53 \\
\hline $\mathbf{2}$ & 0,58 & 4,0293 & 75,43 \\
\hline $\mathbf{3}$ & 0,35 & 2,4738 & 63,26 \\
\hline $\mathbf{4}$ & 0,22 & 1,5117 & 44,10 \\
\hline $\mathbf{5}$ & 0,14 & 0,9533 & 25,46 \\
\hline $\mathbf{6}$ & 0,09 & 0,6261 & 13,23 \\
\hline $\mathbf{7}$ & 0,06 & 0,4279 & 6,74 \\
\hline $\mathbf{8}$ & 0,04 & 0,3031 & 3,52 \\
\hline $\mathbf{9}$ & 0,03 & 0,0221 & 1,91 \\
\hline $\mathbf{1 0}$ & 0,02 & 0,1661 & 1,09 \\
\hline $\mathbf{1 1}$ & 0,02 & 0,1275 & 0,64 \\
\hline $\mathbf{1 2}$ & 0,01 & 0,0999 & 0,40 \\
\hline $\mathbf{1 3}$ & 0,01 & 0,0796 & 0,25 \\
\hline $\mathbf{1 4}$ & 0,01 & 0,0644 & 0,17 \\
\hline $\mathbf{1 5}$ & 0,01 & 0,0528 & 0,11 \\
\hline $\mathbf{1 6}$ & 0,01 & 0,0438 & 0,08 \\
\hline $\mathbf{1 7}$ & 0,01 & 0,0037 & 0,05 \\
\hline $\mathbf{1 8}$ & 0,00 & 0,0311 & 0,04 \\
\hline $\mathbf{1 9}$ & 0,00 & 0,0266 & 0,03 \\
\hline $\mathbf{2 0}$ & 0,00 & 0,0229 & 0,02 \\
\hline & & & \\
\hline
\end{tabular}

After assembling the bench, it is expected to obtain experimental results close to the values shown graphically in Table 3. 
According to calculations shown graphically in Table 3 , the maximum efficiency of the system should be around $80 \%$ and above $50 \%$ for distances up to $4 \mathrm{~cm}$ for wireless energy transfer of low power loads. It will be considered a charge connected to the receiver via USB so that its battery is charged while the distance from the coils is varied. The test results are expected to be consistent with the theory.

\section{CONCLUSION}

For many decades, the concept of WPT has failed to achieve full application due to the lack of commercial semiconductors capable of operating in the required frequency/current condition. Currently, several works seek to improve the compensation techniques to increase the range of applications of this technology. It is noteworthy that power electronics is fundamental for wireless energy transfer, and it is an important subject of research in the area.

The current project developed was divided into stages. In the first stage, a survey of state of the art was carried out to support the development of the bench. After that, the studies followed the research about the inductive link, the most used coil geometries, the more effective number of turns, the better material, and so on. The design of the compensation circuit and other system components was assembled, as well as the specifications for the bench were defined for later acquisition of the materials. At the end of the period defined in the schedule, it is expected to obtain a test bench that will have measurement mechanisms for calculating input and output power, allowing its efficiency to be calculated and the results validated.

\section{Acknowledgments}

To the FIEB SENAI CIMATEC system for its financial and structural contribution, which is fundamental for carrying out the work.

This work was carried out with the support of the coordination of the Embedded Electronics and Generation, Transmission, and Distribution sectors at SENAI CIMATEC.

\section{REFERENCES}

1 SOUZA, Wanberton Gabriel. Análise experimental da transmissão de energia sem fios por modos ressonantes. Dissertação (Mestrado em Engenharia Elétrica) -Faculdade de Engenharia Elétrica, Universidade Federal de Uberlândia, 2016.

${ }^{2}$ ABREU, Reinaldo Lima de. Projeto e Implementação de um Dispositivo para Transferência de Energia Sem Fios por Modos

Autossintonizáveis. 2017.

${ }^{3}$ MOTTA, Tiago da Silva. Transmissão de energia sem fio: método de acoplamento indutivo ressonante. 2016.

4 BANA, Viktor. Maritterization of Coupled Coil in Seawater for Wireless Power Transfer. (No. SPAWAR/SCPTR-2026). Space and Naval Warfare Systems Center Pacific San Diego Ca, 2013.

5 CHEN, Kainan; ZHAO, Zhengming. Analysis of the double-layer printed spiral coil for wireless power transfer. IEEE Journal of Emerging and Selected Topics in Power Electronics, v. 1, n. 2, p. 114-121, 2013.

${ }^{6}$ BARBOSA, Celton Ribeiro. Estudo de sistemas de transferência indutiva de potência para recarga de baterias. 2018.

${ }^{7}$ FERNANDES, RODOLFO C.; AZAURI A. Método de projeto e caracterização de conversores para transferência indutiva de potência. 